\title{
CHAOTISED POLYMERIC HOLLOW FIBRE BUNDLE AS A CROSSFLOW HEAT EXCHANGER IN AIR-WATER APPLICATION
}

\author{
Tereza Krouliková*, Ilya Astrouski, Miroslav Raudenský \\ Brno University of Technology, Faculty of Mechanical Engineering, Heat Transfer and Fluid Flow Laboratory, \\ Technická 2896/2, 61669 Brno, Czech Republic \\ * corresponding author: Tereza.Kroulikova@vut.cz
}

ABstRaCt. Fifteen years ago, polymeric hollow fibre heat exchangers were presented for the first time. Nowadays there are not only the shell-and-tube types as there were at the beginning. In this paper, six chaotised polymeric hollow fibre bundles with a different number of fibres were studied. The bundles presented varied in their fibre diameter, number and shape. These bundles were fixed into the module in such a way that the middle part serves as a cross-flow heat exchanger in an air tunnel. They were tested for air-water application with three different airflow rates. The overall heat transfer coefficients were determined, and the inner and outer heat transfer coefficients were derived. The modules presented achieved a heat transfer rate of up to $1309 \mathrm{~W}$. The overall heat transfer coefficient reached a maximum of $339 \mathrm{~W} \mathrm{~m}^{-2} \mathrm{~K}^{-1}$.

KeYwords: Polymer hollow fibre, chaotic structure, cross-flow heat exchanger, gas-liquid application.

\section{INTRODUCTION}

Polymeric hollow fibre heat exchangers (PHFHE) are an alternative to common metal heat exchangers in low temperature applications. Their advantages are low cost, low weight and corrosion resistance. Their heat transfer surface consists of hundreds or even thousands of fibres with a small outside diameter, commonly $0.4-1.6 \mathrm{~mm}$. Polymeric material provides such advantages as light weight, easy machining and forming, flexibility and corrosion resistance. The disadvantage of polymeric material is its low thermal conductivity $\left(0.1-0.4 \mathrm{~W} \mathrm{~m}^{-1} \mathrm{~K}^{-1}\right)$, which is $100-300$ times lower than metals. The high thermal resistance can be overcome by the hollow fibres having a small diameter and thin wall. According to [1, the wall thickness for PHFHE should be kept below 100 $\mu \mathrm{m}$. PHFHE are mainly made of polypropylene (PP), but also other polymers are used, such as polyamide (PA), polyetheretherketone (PEEK), polyphthalamide (PPA) or asymmetric polyethersulfone (PES).

PHFHE were firstly presented by Zarkadas in [2] fifteen years ago as an alternative to conventional shelland-tube heat exchangers. In his study, the overall heat transfer coefficients were $647-1314 \mathrm{~W} \mathrm{~m}^{-2} \mathrm{~K}^{-1}$ for water-water system and $414-642 \mathrm{~W} \mathrm{~m}^{-2} \mathrm{~K}^{-1}$ for ethanol-water system. As PHFHE are corrosion resistant, they are mainly studied in desalination process 3, 4. But they were also studied for a cooling system of a solar panel [5] or the HVAC (heating, ventilation, air-conditioning) applications [6].

The gas-liquid application was studied in [7], where two PHFHE prototypes were presented as a possible alternative to the aluminium automotive radiator. Two modules with a rectangle cross-section measuring $250 \times 250 \mathrm{~mm}$ were prepared and tested. The $50 / 50 \%$ water glycol solution was used as a coolant.
Both devices achieved similar heat transfer rate, up to $10.4 \mathrm{~kW}$ and high values of the overall heat transfer coefficient, up to $335 \mathrm{~W} \mathrm{~m}^{-2} \mathrm{~K}^{-1}$. That study also mentions the significant influence of the diameter of the polymeric hollow fibre on heat transfer coefficients on both inner and outer surfaces of the fibre.

In order to provide direct contact between the fibres and the surrounding stream of fluid, it is necessary to separate fibres from each other to let the fluid flow between them. Unseparated fibres have an extensive mutual contact, therefore, they are blocking themselves and only a few of them are active. A method of separation of bundles is chaotisation, which was presented in 8 . The fibres are deformed by stretching and then thermal fixation of the shape generated by stretching is applied. This provides direct contact between fibres and the surrounding fluid and enables better heat transfer.

Chaotised bundles were studied as immersed heat exchangers in a hot water reservoir [9]. Three bundles with two different diameters were put into a hot water reservoir. The results obtained showed a high value of heat transfer rate, up to $22.76 \mathrm{~kW}$. Their analysis also indicates a strong dependence of overall heat transfer coefficient on the quality of the fibre distribution.

The polymer material is generally more resistant to fouling than metals [1]. The fouling of PHFHEs was studied in 10] and [11. The particulate fouling in [10] decreased the overall heat transfer coefficient by $20 \%$ and defouling by air-bubbling was found as efficient. The fouling in shower wastewater and laundry wastewater was studied in [11]. In the first experiment, no significant decrease of overall heat transfer coefficient was observed during the two-week experiment. In the latter case, the overall heat transfer coefficient dropped from $1747 \mathrm{~W} \mathrm{~m}^{-2} \mathrm{~K}^{-1}$ to $963 \mathrm{~W} \mathrm{~m}^{-2} \mathrm{~K}^{-1}$ 
and the surface of the fibres was covered by biofilm and solid particle deposit. Both mentioned papers concern liquid applications, there are no fouling data specifically for PHFHEs for a gas application.

The yield strength of polymers is much lower than the yield strength of metals [1. This can limit the minimal wall thickness without compromising the physical integrity of the heat exchanger structure.

PHFHE are a promising alternative in applications, which require non-corrosive and clean materials or where weight plays a major role, for example, heat recovery systems or HVAC systems. Chaotised PHFHE are elastic and flexible, which allows for the use of some design variants, which can improve the overall heat transfer and utilise some spaces, which are not suitable for non-flexible heat exchangers.

In the presented study the chaotised polymeric hollow fibre bundles were used as the cross-flow heat exchanger. As material, the polypropylene was chosen, since it is easy to make the chaotised bundles from it. Six modules were made, tested and compared in an air-water application.

\section{EXPERIMENT}

In the laboratory, six modules (M-200 - M-1200) with a different number of fibres were prepared from chaotised polypropylene hollow fibre bundles. The bundles were put inside a box and plastered in such a way that there is a passage with a square cross-sectional area $(100 \times 100 \mathrm{~mm})$, see Fig. 2 The only active heat transfer surface is in the passage. Three modules were made of fibre with an outside diameter of $0.6 \mathrm{~mm}$ and the other three with a diameter of $0.8 \mathrm{~mm}$. In both cases, the wall thickness is $10 \%$ of the fibre outer diameter. Those are the most common fibre dimensions used in gas-liquid applications. All the modules differ in the number of fibres used. The average over-length was defined as a way of measuring the rate of the chaotisation. It is the ratio of an average length of a fibre in the active area to the width of the tunnel passage. Over-length influences the ratio between the heat transfer area and the volume of the bundle. The parameters of the tested bundles are given in Table 1

Those modules were placed in an air tunnel, see Fig. 3. The air circulation inside the tunnel was ensured by a small fan and water flowed inside the hollow fibre modules. The flow rate and temperature of the water were controlled and maintained as required by external equipment (test circuit of the calorimetric room). The actual water flow rate was measured by the magnetic-inductive flowmeter Krohne OPTIFLUX 4300 (measuring tube DN10) and recorded by a data acquisition system. The flowmeter is calibrated and ensures precision of $\pm 0.2 \%$. The water and air temperature were measured by Pt100 1/3 class A temperature sensors $\left( \pm 0.1 \mathrm{~K}\right.$ precision in $0-80{ }^{\circ} \mathrm{C}$ temperature range). The water temperature sensors were connected to a data acquisition system of the testing circuit and the air temperature sensors were

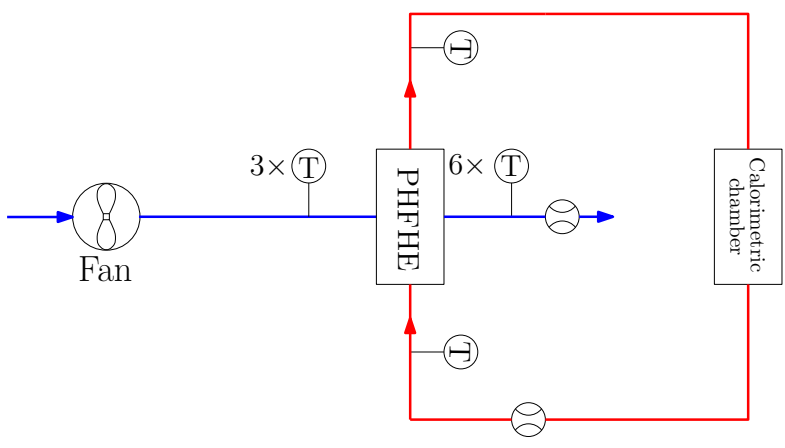

Figure 1. Scheme of the test rig.

connected to National Instrument NI-9217 modules. The air flow rate was measured by the portable hot wire anemometer Omega HHF-SD1 (calibrated with precision $\pm 5 \%$ ) placed in the tunnel $30 \mathrm{~cm}$ behind the tested bundle.

Three temperature sensors Pt100 were placed in front of the module and six behind the module. The average temperatures values of $T_{c, \text { in }}$ and $T_{c, \text { out }}$, air inlet and air outlet respectively, are calculated from the temperatures measured. Then, the air and water flows were monitored.

All modules were tested three times with different air and water flow rates. In all runs, the water flow rate was adjusted in such a way that the inlet temperature was $75^{\circ} \mathrm{C}$ and the outlet temperature was $65^{\circ} \mathrm{C}$, thus the difference in water temperature was $10 \mathrm{~K}$.

\section{DATA REDUCTION}

Firstly, the thermophysical properties of the water and the air were calculated based on the average of the inlet and outlet temperature of liquids. The properties of water were considered to be temperature dependent and were calculated using the following formulas. The viscosity:

$$
\begin{aligned}
\mu=\exp & \left(-6.358-2.88 \cdot 10^{-2} T+1.31 \cdot 10^{-4} T^{2}\right. \\
& \left.-2.58 \cdot 10^{-7} T^{3}\right),
\end{aligned}
$$

the specific heat capacity:

$$
\begin{aligned}
& c_{p}=1.3410^{-9} T^{6}-4.9506 \cdot 10^{-7} T^{5}+ \\
& 7.09647 \cdot 10^{-5} T^{4}-0.004864569 T^{3}+0.16759809 T^{2} \\
& -2.81027645351 T+4201.37207,
\end{aligned}
$$

the thermal conductivity:

$$
k=5.76 \cdot 10-1+1.77 \cdot 10^{-3} T-6.37 \cdot 10^{-6} T^{2}
$$

and the density:

$$
\rho=1001-0.0672 T-4.04 \cdot 10^{-3} T^{2}+4.94 \cdot 10^{-6} T^{3},
$$

where in all the above formulas, $T$ is temperature in ${ }^{\circ} \mathrm{C}$. Thermophysical properties of the air were interpolated from the table in the appendix of 12 . 


\begin{tabular}{lccccc}
\hline Module & $\begin{array}{c}\text { No. of } \\
\text { active fibres }\end{array}$ & $\begin{array}{c}\text { Outer diameter } \\
\text { of fibre }[\mathrm{mm}]\end{array}$ & $\begin{array}{c}\text { Inner diameter } \\
\text { of fibre }[\mathrm{mm}]\end{array}$ & $\begin{array}{c}\text { Total outer } \\
\text { surface area }\left[\mathrm{m}^{2}\right]\end{array}$ & $\begin{array}{c}\text { Average } \\
\text { overlength }\end{array}$ \\
\hline M-200 & 186 & 0.8 & 0.64 & 0.111 & 2.38 \\
M-300 & 199 & 0.6 & 0.48 & 0.064 & 1.7 \\
M-400 & 320 & 0.8 & 0.64 & 0.193 & 2.4 \\
M-600 & 440 & 0.6 & 0.48 & 0.167 & 2.01 \\
M-800 & 530 & 0.8 & 0.64 & 0.318 & 2.39 \\
M-1200 & 1049 & 0.6 & 0.48 & 0.402 & 2.03 \\
\hline
\end{tabular}

TABLE 1. Characteristics of tested modules.

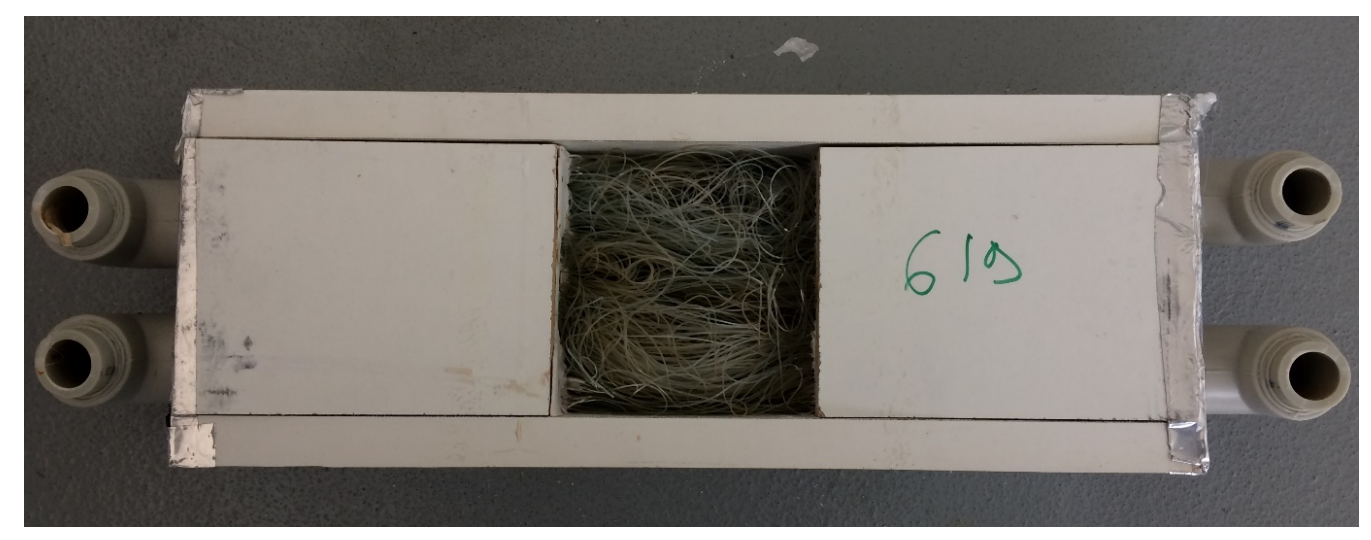

FiguRE 2. One of the tested modules.

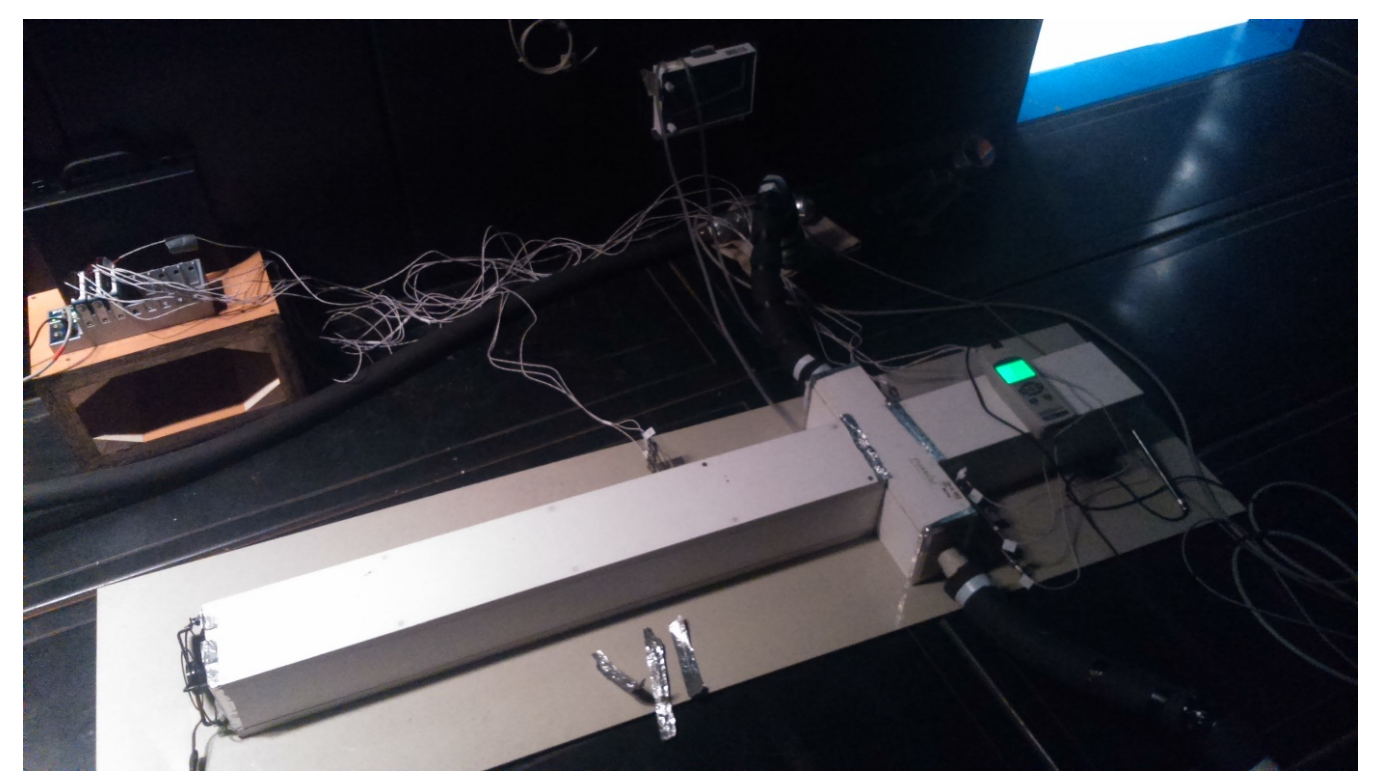

FiguRE 3. Experimental tunnel. 
The overall heat transfer coefficient of the cross-flow PHFHE without phase change can be obtained from:

$$
\begin{gathered}
Q=\dot{m}_{h} c_{p, h}\left(T_{h, \text { in }}-T_{h, \text { out }}\right) \\
=\dot{m}_{c} c_{p, c}\left(T_{c, \text { out }}-T_{c, \text { in }}\right), \\
U_{i}=\frac{Q}{\triangle T_{l m} A_{i} F},
\end{gathered}
$$

where $Q$ is the heat transfer rate, $\dot{m}_{h}, \dot{m}_{c}$ are mass rates and $c_{p, h}, c_{p, c}$ are specific heat capacities of hot water and cold air respectively, $U_{i}$ is the overall heat transfer area based on the inner area, $A_{i}$ is the inner area and $\triangle T_{l m}$ is log mean difference temperature calculated from:

$$
\Delta T_{l m}=\frac{\left(T_{h, \text { in }}-T_{h, \text { out }}\right)}{\ln \left(\frac{T_{h, \text { in }}-T_{c, \text { out }}}{T_{h, \text { out }}-T_{c, \text { in }}}\right)}
$$

and $\mathrm{F}$ is the correction factor, which is calculated by:

$$
F=\frac{\mathrm{NTU}_{c f}}{\mathrm{NTU}}
$$

where $\mathrm{NTU}_{c f}$ is the so called number of transfer units of counterflow heat exchanger and NTU is the number of transfer units of the tested heat exchanger. The actual correction factor and overall heat transfer coefficient must be calculated simultaneously based on the experimental data, therefore, the NTU was computed by a formula for a single pass cross-flow heat exchanger with one fluid mixed and one unmixed 12, 13 .

To calculate the tube-side and air-side heat transfer coefficients, $h_{i}$ and $h_{o}$, the approach proposed by Hickman was used [2]. The formulas for Nusselt number under the boundary condition of third kind $\mathrm{Nu}_{T 3}$, wall Nusselt number $\mathrm{Nu}_{w}$ and the reciprocal of the lumped resistance term $1 / U_{w}$, the wall heat transfer coefficient, are given by:

$$
\begin{gathered}
\mathrm{Nu}_{T 3}=\frac{\frac{48}{11}+\mathrm{Nu}_{w}}{1+\frac{59}{220} \mathrm{Nu}_{w}} \\
\mathrm{Nu}_{w}=\frac{U_{w} D_{i}}{k_{i}} \\
\frac{1}{U_{w}}=\frac{D_{i}}{D_{o} h_{o}}+\frac{D_{i}}{2 k_{w}},
\end{gathered}
$$

where $D_{o}$ and $D_{i}$ are the outer and inner diameter of the hollow fibre, $k_{i}$ is the thermal conductivity of water, $k_{w}$ is the thermal conductivity of the polypropylene wall, $0.18 \mathrm{~W} \mathrm{~m}^{-1} \mathrm{~K}^{-1}$. The overall Nusselt number can be calculated using

$$
\begin{aligned}
\frac{1}{\mathrm{Nu}_{o v}} & =\frac{k_{i}}{U_{i} D_{i}}=\frac{1}{\mathrm{Nu}_{T 3}}+\frac{1}{\mathrm{Nu}_{w}}, \\
\frac{1}{U_{i}} & =\frac{1}{h_{i}}+\frac{1}{U_{w}}
\end{aligned}
$$

where the tube-side heat transfer coefficient is computed from the inside Nusselt number:

$$
h_{i}=\frac{\mathrm{Nu}_{T 3} k_{i}}{d_{i}} .
$$

After some manipulation, a quadratic equation can be obtained

$$
\begin{aligned}
\left(1-\frac{59}{220} \mathrm{Nu}_{o v}\right) \mathrm{Nu}_{w}^{2}+ & \left(\frac{48}{11}-2 \mathrm{Nu}_{o v}\right) \mathrm{Nu}_{w} \\
& -\frac{48}{11} \mathrm{Nu}_{o v}=0
\end{aligned}
$$

and its solutions are a positive and a negative root. The positive one is considered to be the wall Nusselt number. This approach allows us to determine both heat transfer coefficients based on the experimentally obtained overall heat transfer coefficient.

\section{Results And Discussion}

All experiments were done with the tube-side Reynolds number in the range of $38-667$, therefore, all experiments were done with the tube-side flow in the laminar regime. The air speed was relatively low, max. $4.5 \mathrm{~m} \mathrm{~s}^{-1}$. Tab. 2 contains a range of results of all 18 experiments, such as the Reynolds number $\mathrm{Re}_{t u b e}$, the air speed $v_{a i r}$, the heat transfer rate $Q$, the overall heat transfer coefficient based on the outer fibre surface $U_{o}$, and air-side and tube-side heat transfer coefficients, $h_{o}$ and $h_{i}$ respectively.

The Fig. 4 shows the heat transfer rate (the average of the hot and cold side) dependent on tube flow and air speed. The heat transfer rate was up to $1309 \mathrm{~W}$ for the module M-400, but also three others were over $1200 \mathrm{~W}$. It can be seen that the heat transfer rate on the tube side depends on the tube flow since the difference between the inlet and outlet temperature was set to be the same for all runs.

The heat transfer rate on the air side is obviously affected by the air speed and the surface area, i.e., the number of fibres and their diameters. The M-1200 module's heat transfer surface is larger than M-800 module's one, but its performance is the same as the M-800. The heat transfer area of the module M-1200 is too large and inefficient. Also, it is possible, that there are too many fibres in the volume that they block each other even though they are separated by chaotisation.

The overall heat transfer coefficient was up to $339 \mathrm{~W} \mathrm{~m}^{-2} \mathrm{~K}^{-1}$. But not only the maximum value is high, see Fig. 5. For example, [14] denotes $25-55 \mathrm{~W} \mathrm{~m}^{-2} \mathrm{~K}^{-1}$ as the approximate values of the overall heat transfer coefficient for a finned-tube heat exchanger. It is true that those values incorporate the fouling factor, which is not available for the PHFHE since there has been little study of this issue.

The air-side heat transfer coefficient behaves similarly to the overall heat transfer coefficient, see Fig. 5 It is dependent on the air speed and the outer diameter. The modules with $D_{o}=0.8$ (M-200, M-400 


\begin{tabular}{lcccccc}
\hline Module & $v_{\text {air }}\left[\mathrm{m} \mathrm{s}^{-1}\right]$ & $\Re_{\text {tube }}$ & $Q[\mathrm{~W}]$ & $U_{o}\left[\mathrm{~W} \mathrm{~m}^{-2} \mathrm{~K}^{-1}\right]$ & $h_{o}\left[\mathrm{~W} \mathrm{~m}^{-2} \mathrm{~K}^{-1}\right]$ & $h_{i}\left[\mathrm{~W} \mathrm{~m}^{-2} \mathrm{~K}^{-1}\right]$ \\
\hline M-200 & $0.3-4.3$ & $105-666$ & $157-1033$ & $53-248$ & $56-307$ & $\sim 4525$ \\
M-300 & $0.5-4.3$ & 194.614 & $234-861$ & $129-339$ & $139-423$ & $\sim 6035$ \\
M-400 & $0.5-3.8$ & $111-396$ & $290-1309$ & $65-226$ & $69-274$ & $\sim 4530$ \\
M-600 & $0.5-3.0$ & $86-449$ & $241-1270$ & $61-290$ & $64-349$ & $\sim 6047$ \\
M-800 & $0.4-2.4$ & $53-267$ & $235-1206$ & $35-179$ & $36-208$ & $\sim 4535$ \\
M-1200 & $0.5-2.3$ & $39-183$ & $259-1222$ & $29-152$ & $30-167$ & $\sim 6059$ \\
\hline
\end{tabular}

TABLE 2. Compilation of results.
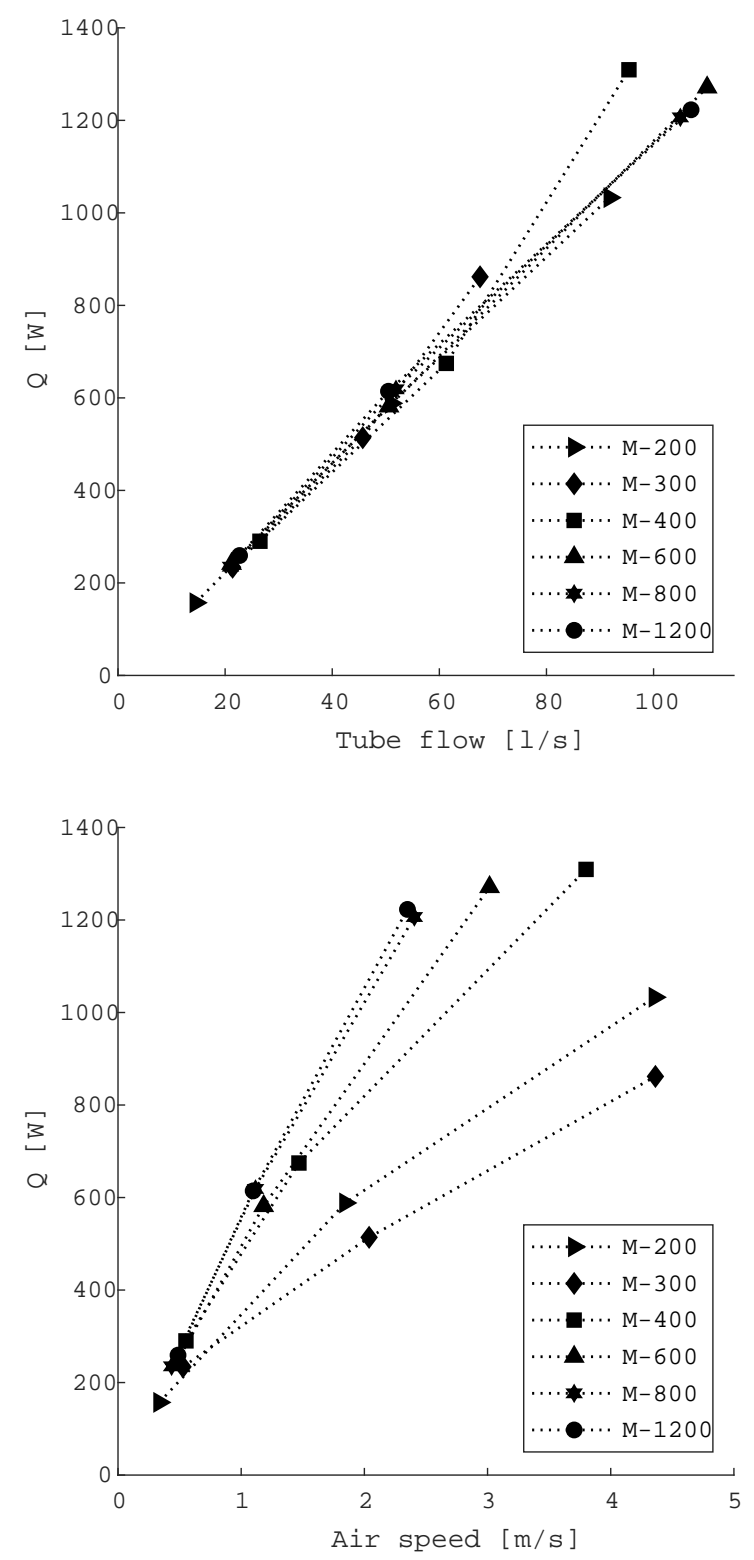

FigURE 4. Heat transfer rate of tested modules.

and M-800) follow the same trend. This is not true in the case of the modules with $D_{o}=0.6$ (M-300, M-600, M-1200). For the module M-1200, the heat transfer coefficient achieved the lowest values, as was said above, this module is large and inefficient. If we compare modules M-300 and M-600, which differs in
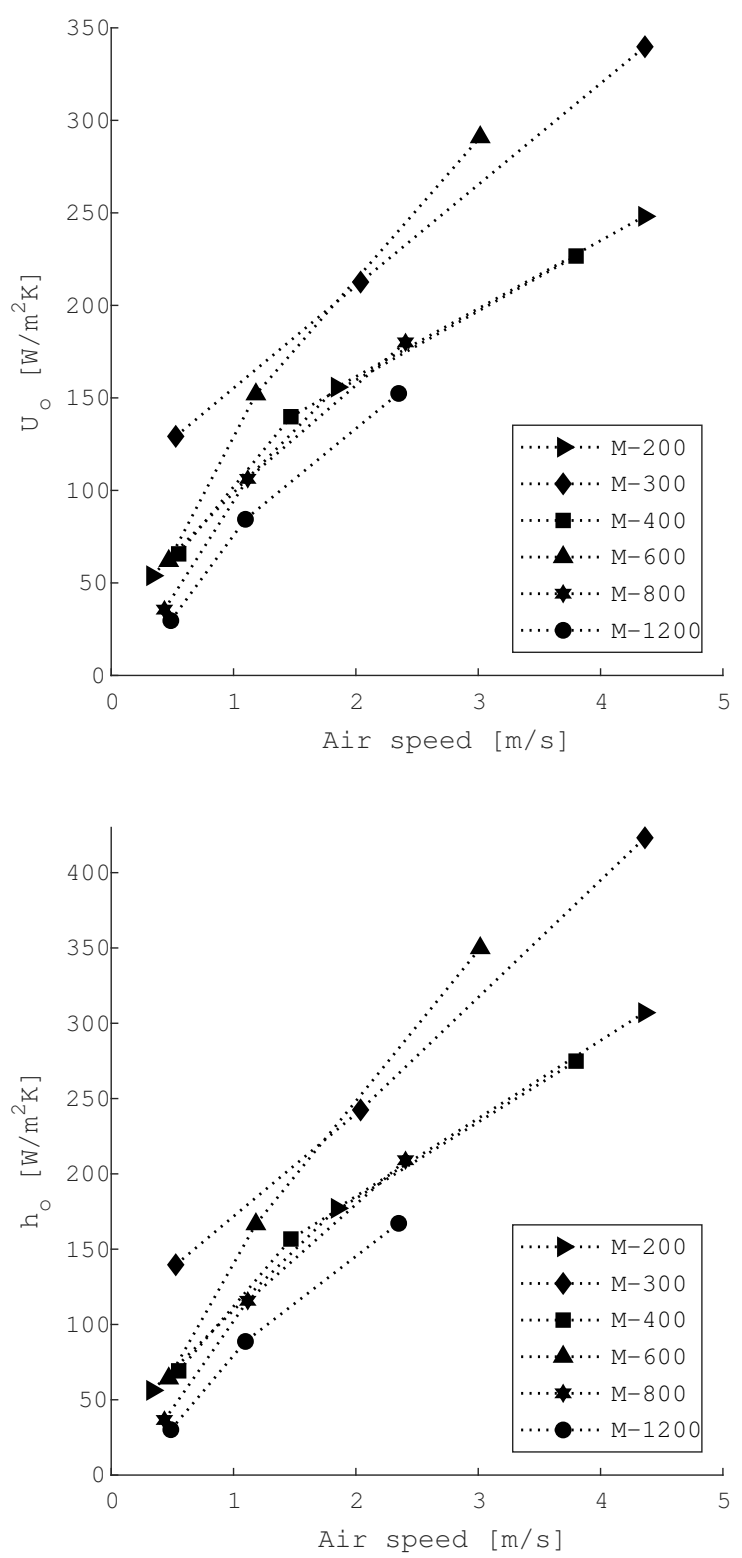

Figure 5. Overall heat transfer coefficient and the outside heat transfer coefficient of tested modules.

the average overlength, we see that the M-300 (with a lower average overlength) grows faster with the air speed.

As defined, the overlength has an influence on the ratio of heat transfer surface to volume and, in this 
case, also to the active length of the fibres. In this study, the higher overlength means bigger heat transfer surface, which positively affects the heat transfer rate. Obviously, the modules with higher overlength are having lower values of air-side and overall heat transfer coefficient. But it must be considered that they also have a bigger diameter and the outer heat transfer coefficient rises with a decreasing tube diameter 8.

If we compare the air-side transfer coefficient of the chaotised PHFHE with PHFHE with a woven heat transfer surface in previous publications [7, 15, the chaotised one is lower. Also, if we look at Fig. 5 on the lower graph, we see that the module M-300, which has the lowest over-length, has the highest $h_{o}$.

It seems the chaotisation lowers the heat transfer coefficient, but only in the case of the separated HE. As was shown in [8], the straight bundle achieved significantly lower overall heat transfer coefficient than the chaotised one. In chaotised HE, the different parts of the fibre are actually in different flow arrangements, unlike the woven heat transfer surface used in [7, 15. With higher over-length, more heat transfer surface is in a parallel-flow arrangement and is, therefore, less efficient.

By contrast, the tube-side heat transfer coefficient is much higher than the air-side heat transfer coefficient. Its value was not affected by the set up of the flow. This behaviour is in concordance with the fact, that the inside flow is laminar, the Nusselt number is constant and therefore independent of the flow. However, the tube-side heat transfer coefficient is dependent on the fibre inner diameter. The decrease in the diameter results in a rapid increase of $h_{i}$.

\section{Conclusions}

The thermal performance of six modules made from chaotised bundles was studied. The chaotisation of fibres contributes to a good distribution of fibres in a heat exchanger. This is needed to enable the medium to access the whole heat transfer surface. The overall heat transfer coefficient achieved up to $339 \mathrm{~W} \mathrm{~m}^{-2} \mathrm{~K}^{-1}$. The tube-side heat transfer coefficient was not affected by the flow rate inside the fibre since the experiments were done in a laminar regime. But it was influenced by the fibre diameter. For a larger diameter, it was lower. Their performance is not as good as the performance of woven heat transfer surfaces. But chaotisation is cheaper and easier. In addition to this, the polymer hollow fibre heat exchangers are lightweight, cheap, and therefore suitable to replace some metal heat exchangers in low-temperature applications.

\section{ACKNOWLEDGEMENTS}

This work was supported by the Ministry of Education, Youth and Sports of the Czech Republic under OP RDE grant number CZ.02.1.01/0.0/0.0/16 019/0000753" Research centre for low-carbon energy technologies".

\section{REFERENCES}

[1] X. Chen, Y. Su, D. Reay, S. Riffat. Recent research developments in polymer heat exchangers - A review. Renewable and Sustainable Energy Reviews 60:1367-1386, 2016. DOI:10.1016/j.rser.2016.03.024.

[2] D. M. Zarkadas, K. K. Sirkar. Polymeric Hollow Fiber Heat Exchangers. Industrial and Engineering Chemical Research 43(25):8093-8106, 2004. DOI:10.1021/ie040143k

[3] L. Song, B. Li, D. Zarkadas, et al. Polymeric hollowfiber heat exchangers for thermal desalination processes. Industrial and Engineering Chemistry Research 49(23):11961-11977, 2010. DOI:10.1021/ie100375b

[4] S. Song, H. Shan, J. Liu, B. Li. Heat transfer study of PVDF hollow fiber heat exchanger for desalination process. Desalination 446:1-11, 2018. DOI:10.1016/j.desal.2018.08.016.

[5] M. Schmidt, I. Astrouski, M. Reppich, M. Raudensky. Solar panel cooling system with hollow fibres. Applied Solar Energy 52(2):86-92, 2016. DOI:10.3103/S0003701X16020213

[6] Y. Qin, B. Li, S. Wang. Experimental investigation of a novel polymeric heat exchanger using modified polypropylene hollow fibers. Industrial and Engineering Chemistry Research 51(2):882-890, 2012. DOI:10.1021/ie202075a

[7] I. Krásný, I. Astrouski, M. Raudenský. Polymeric hollow fiber heat exchanger as an automotive radiator. Applied Thermal Engineering 108:798-803, 2016. DOI:10.1016/j.applthermaleng.2016.07.181

[8] M. Raudenský, I. Astrouski, M. Dohnal. Intensification of heat transfer of polymeric hollow fiber heat exchangers by chaotisation. Applied Thermal Engineering 113:632638, 2017. DOI:10.1016/j.applthermaleng.2016.11.038

[9] K. Weiß, I. Astrouski, M. Reppich, M. Raudenský. Polymeric Hollow-Fiber Bundles as Immersed Heat Exchangers. Chemical Engineering \& Technology 41(7):1457-1465, 2018. DOI:10.1002/ceat.201700014.

[10] I. Astrouski, M. Raudenský, M. Dohnal. Particulate fouling of polymeric hollow fiber heat exchanger. In Proceedings of Internationall Conference on Heat Exchanger Fouling and Cleaning. 2013.

[11] M. Astrouski, I., Raudensky, M., \& Dohnal. Fouling of Polymeric Hollow Fiber Heat Exchanger by Wastewater. Chemical Engineering Transactions 45(2006):949-954, 2015. DOI:10.3303/CET1545159

[12] T. L. Bergman, F. P. Incropera, D. P. Dewitt, A. S. Lavine. Fundamentals of heat and mass transfer. Wiley, Hoboken, NJ, 7th edn., 2011.

[13] W. M. Kays, A. L. London. Compact heat exchangers. Krieger Pub. Co., Malabar, Fla., 1998.

[14] J. P. Holman. Heat Transfer. Elsevier, 10th edn., 2010.

[15] I. Astrouski, M. Raudenský. Polymeric Hollow Fiber Heat Exchangers: Liquid-to-Gas Application. In ASHRAE TRANSACTIONS 2014, VOL 120, PT 2, vol. 120, pp. 95-105. ASHRAE, 2014. 